\title{
INOVAÇÃO SUSTENTÁVEL: ESTRATÉGIA EM EMPRESAS DO SETOR QUÍMICO
}

\author{
Uiara Gonçalves De Menezes \\ Mestre em Administração pela Universidade Federal de Santa Maria - UFSM \\ Professora da Faculdade dos Imigrantes - FAI \\ uiara.menezes@gmail.com \\ Jordana Marques Kneipp \\ Mestranda em Administração da Universidade Federal de Santa Maria - UFSM \\ jordanakneipp@yahoo.com.br

\section{Luciana Aparecida Barbieri} \\ Mestranda em Administração da Universidade Federal de Santa Maria - UFSM \\ lucianaaparecidabarbieri@yahoo.com.br
}

\section{Clandia Maffini Gomes}

Doutora em Administração pela Universidade de São Paulo - USP

Professora da Universidade Federal de Santa Maria - UFSM

clandia@smail.ufsm.br

\section{RESUMO}

O objetivo do presente estudo consiste em identificar como as empresas do setor químico brasileiro gerenciam as práticas de inovação orientadas para a sustentabilidade. Mais especificamente foi explorado um segmento da indústria química caracterizado pela produção de sabões, detergentes, produtos de limpeza, cosméticos, perfumaria e higiene pessoal. Para tanto, foram analisadas três indústrias que possuem reconhecidas práticas de inovação e sustentabilidade. Os dados do estudo, qualitativo e descritivo, foram obtidos a partir de entrevistas semiestruturadas com diretores de P\&D e complementados por dados secundários publicados em relatórios de sustentabilidade e websites das companhias. As análises dos dados obtidos evidenciaram que as empresas possuem investimentos em eco-eficiência nos produtos e processos, desenvolvem parcerias com universidade para geração de tecnologia, acompanham as demandas de mercado e apresentam o conceito de sustentabilidade integrado na cadeia de valor empresarial. Ressalta-se, entretanto, uma característica pouco explorada pelas empresas consiste na inclusão da gestão sustentável na ampliação do sistema de produto-serviço.

Palavras-Chave: Sustentabilidade; Gestão da inovação e Indústria química.

\section{SUSTAINABLE INNOVATION: BUSINESS STRATEGY IN CHEMICAL INDUSTRY}

\begin{abstract}
The study identifies how companies in the Brazilian chemical industry manage the practices of innovation-oriented sustainability. More specifically it focuses on one segment of the chemical industry characterized by the production of soaps, detergents, cleaning products, cosmetics, perfumes and toiletries. The study analyzed three industries which have recognized practices of innovation and sustainability. The data of the study, both qualitative and descriptive, were obtained from semi-structured interviews with the directors of R\&D and supplemented by data published in sustainability reports and companies' websites. The analyses shows the companies have investments in eco-efficiency of products and processes, develops partnerships with universities for technology improvement, track market demands and present the concept of sustainability integrated to the business value chain. The inclusion of management practices based on the expansion of the product-service system was a characteristic less explored by companies.
\end{abstract}

Key-words: Sustainability; Management innovation and Chemical Industry.

Revista de Gestão Social e Ambiental - RGSA, São Paulo, v. 5, n. 2, p. 96-111, mai./ago. 2011. 


\section{INTRODUÇÃO}

A inovação representa um fator essencial para obtenção de vantagem competitiva, sendo que cada vez mais, as organizações são estimuladas a incorporarem práticas inovadoras nas suas estratégias de negócio. Nesse sentido, Gomes, Krugliankas, Horneau Júnior e Scherer (2009) ressaltam que o estímulo à inovação requer o entendimento da tecnologia, do processo de inovação e de como as políticas afetam o comportamento inovador da empresa.

Quando associada à questão ambiental, a inovação pode propiciar o surgimento de inovações tecnológicas importantes, que podem ser pequenas melhorias nas atividades de rotina e até mesmo grandes modificações de produtos e processos que visam o alcance das metas organizacionais. Uma organização com conhecimento sobre o mercado e foco em pesquisa e desenvolvimento (P\&D) aumenta suas chances de desenvolver novas soluções que podem ampliar a sua vantagem competitiva e gerar oportunidades de negócios (Daroit; Nascimento, 2000).

A geração de inovação tecnológica pode representar uma estratégia de competitividade para as empresas, conforme enfatizado por Teigland, Fey e Birkinshaw (2000), ao considerarem que parte do sucesso das organizações está associado a sua capacidade de criar uma vantagem competitiva através da introdução de novas tecnologias.

Com o intuito de conciliar inovação e sustentabilidade, a indústria química vem focando esforços no desenvolvimento de atividades que visam à sustentabilidade do seu processo produtivo, principalmente no que se refere às questões sociais e ambientais. Os produtos químicos possuem ampla abrangência, tendo em vista que são fornecidos para quase todos os tipos de indústrias, dessa forma, qualquer modificação na composição de determinadas substâncias, visando menor agressão ao ambiente, permeará por quase toda a cadeia de produção da indústria, e esse resultado será percebido por meio da redução do impacto ambiental (Associação Brasileira da Indústria Química ABIQUIM (2009).

Segundo a ABIQUIM (2009), a indústria química participa de quase todas as cadeias e complexos industriais, desempenhando papel de destaque no desenvolvimento das diversas atividades econômicas do país. Também convém destacar a sua representatividade na economia brasileira, tendo como base dados de 2009, o faturamento líquido da indústria, considerando todos os segmentos que a compõem, alcançou R \$ 206,7 bilhões e a sua participação estimada no PIB total foi de $2,6 \%$.

A representatividade do setor químico brasileiro e a relevância da temática do desenvolvimento sustentável nos mais diversos contextos e setores justificam a realização desse estudo, cujo principal interesse consiste em identificar como as empresas do setor químico brasileiro, mais especificamente as produtoras de sabões, detergentes, produtos de limpeza, cosméticos, perfumaria e higiene pessoal, gerenciam as práticas de inovação orientadas para a sustentabilidade. Esse segmento da indústria é definido pela Classificação Nacional de Atividades Econômicas (CNAE) (ABIQUIM, 2009).

Este artigo tratará inicialmente do aporte teórico que sustenta a presente pesquisa, abordando temas referentes à sustentabilidade nas organizações e inovação tecnológica sustentável. A seguir apresenta-se o método seguido da análise dos resultados e por fim as considerações finais.

\section{A SUSTENTABILIDADE COMO FERRAMENTA DE GESTÃO NAS ORGANIZAÇÕES}

A idéia de desenvolvimento sustentável vem sendo debatida amplamente, por muitos grupos e de diversas maneiras, conforme apontado por Brito e Lombardi (2007). Dentre os principais acontecimentos históricos relacionados a questão ambiental, destaca-se em 1983 a criação pelas Nações Unidas da Comissão Mundial sobre Meio Ambiente e Desenvolvimento (CMMAD), a fim de harmonizar o desenvolvimento econômico e a conservação ambiental. A partir da sua criação, diversos estudos convergiram para um relatório sobre o meio ambiente, intitulado Relatório

Revista de Gestão Social e Ambiental - RGSA, São Paulo, v. 5, n. 2, p. 96-111, mai./ago. 2011. 
Brundtland, em homenagem a presidente da Comissão na época, Gro Harlem Brundtland. Neste relatório, divulgado em 1987, ficou estabelecido que os governos signatários deveriam se comprometer com a preservação do ambiente, sendo definido o conceito de desenvolvimento sustentável como o desenvolvimento capaz de suprir as necessidades da geração atual, sem comprometer a capacidade de atender as necessidades das futuras gerações (Nações Unidas da Comissão Mundial sobre Meio Ambiente e Desenvolvimento [CMMAD] (1991). O Relatório Brundtland teve grande importância, pois aliou a concepção do desenvolvimento sustentável com desenvolvimento econômico.

Neste sentido, surge gradativamente um novo enfoque no âmbito organizacional, voltado para o desenvolvimento sustentável, que busca unir o bem-estar econômico, a equidade social e a proteção ao meio ambiente.

As organizações sustentáveis são aquelas que desenvolvem suas práticas e estratégias gerenciais a fim de serem economicamente viáveis, mantendo-se competitivas no mercado, produzindo de maneira a não agredir o meio ambiente e contribuindo para o desenvolvimento social da região e do país onde atuam (Almeida, 2002; Leal, 2009).

Na visão de Almeida (2002), o desafio consiste em colocar os conceitos de desenvolvimento sustentável em prática. Scharf (2004) corrobora com esta afirmação, pois justifica que o desenvolvimento sustentável envolve uma mudança na cultura da organização, de seus funcionários e demanda tempo e recursos financeiros.

Segundo Leal (2009), a construção de um futuro sustentável no contexto organizacional depende rigorosamente do estabelecimento de mudanças corporativas e da adoção de práticas gerenciais transparentes que valorizem as dimensões sociais e ambientais, melhorando a qualidade de vida, o bem-estar social, o equilíbrio econômico entre as nações e o respeito ao meio ambiente.

Para que as empresas consigam praticar os conceitos de desenvolvimento sustentável Elkington (2001), propõe que sejam considerados sempre os aspectos ambientais, sociais e econômicos e que se estabeleçam alguns critérios como: a) democracia e estabilidade política; b) paz; c) respeito à lei e à propriedade; d) respeito aos instrumentos de mercado; e) ausência de corrupção; f) transparência e previsibilidade de governos; g) reversão do atual quadro de concentração da renda em esferas local e global.

O paradigma da sustentabilidade apresenta uma série de desafios para as organizações, sendo que novos pressupostos e práticas surgem no intuito de agregar a sustentabilidade ao contexto organizacional.

De acordo com Hawken, Lovins e Lovins (2000) a sustentabilidade do planeta depende de um novo modelo de capitalismo, denominado capitalismo natural, que se fundamenta na valorização dos seres e sistemas vivos, na dignidade humana e na promoção de melhores condições de trabalho e de vida. Dessa forma, o capitalismo natural apóia-se nas necessidades coletivas e não mais somente nos interesses financeiros das empresas. Nesse sentido, os autores enfatizam a necessidade de alteração na relação entre produtor e consumidor, a partir da transformação de uma economia em que os bens são produzidos e vendidos, em uma economia de serviço e de fluxo, na qual os consumidores obtêm serviços ou invés de produtos, a partir do empréstimo ou aluguel dos bens ao invés da compra. Essa lógica pressupõe a criação de sistemas que assegurem a circulação dos bens ao invés do simples uso e descarte.

Para Manzini e Vezzoli (2003) a adoção de um modelo de negócios baseado em um sistema que substitua a compra de produtos pela aquisição de um serviço é interessante, pois implica em novos tipos de relacionamentos entre stakeholders e parceiros, além do surgimento de novos interesses econômicos e, ainda, na otimização de recursos. Usando menos recursos, tem-se menor custo e todos os stakeholders se beneficiam com os ganhos. Mont (2002) reforça esta idéia, colocando que o objetivo econômico de uma economia funcional consiste na criação do mais alto valor de uso pelo maior tempo possível, através do consumo de menos recursos materiais e energia. 
Outro conceito que merece destaque e que vem sendo difundido no sentido de abordar aspectos inerentes a sustentabilidade refere-se a eco-eficiência. $\mathrm{O}$ conceito de eco-eficiência foi introduzido em 1992, pelo World Business Council for Sustainable Development (WBCSD), representando uma alternativa para reduzir o impacto no ambiente, assegurando, ao mesmo tempo, o crescimento e o desenvolvimento econômico (Verfaillie e Bidwell, 2000).

A World Business Council for Sustainable Development [WBCSD] (2000) define a ecoeficiência como uma filosofia de gerenciamento estratégico voltada para a gestão da sustentabilidade da empresa combinando o desempenho econômico e ambiental, de modo a criar e promover valores com menor impacto sobre o meio ambiente. Corroborando, Lins e Wajnberg (2007), identificam a eco-eficiência como um fator importante em qualquer empresa que esteja buscando a utilização sustentável de recursos naturais, já que concilia o uso sustentável de recursos finitos com eficiência produtiva e redução de custos.

Porém, convém destacar que a ecoeficência não deve ser considerada sinônimo de sustentabilidade corporativa, uma vez que engloba apenas duas das dimensões da sustentabilidade (Almeida, 2007). Nesse sentido, o WBCSD (2000) coloca que a eco-eficiência integra somente dois dos três pilares da sustentabilidade, a economia e a ecologia, ficando o terceiro, o progresso social, de fora do seu âmbito. Assim, muitas organizações desenvolvem conjuntamente com a ecoeficiência práticas de Responsabilidade Social Corporativa (RSC), a fim de integrarem a preocupação com a questão social.

O Instituto Ethos (2009) avalia a responsabilidade social corporativa (RSC) por estar relacionada com a ética e a transparência na gestão e deve refletir-se nas decisões cotidianas que podem causar impactos na sociedade, no meio ambiente e no futuro dos próprios negócios. Em sentido amplo, a responsabilidade social corporativa tem seu surgimento vinculado aos diferentes conceitos associados à responsabilidade existente entre a organização e as diferentes partes interessadas (stakeholders) aos seus negócios (Zanca, Araujo, Quelhas e Costa, 2008).

A RSC é o compromisso das empresas em contribuir para o desenvolvimento econômico sustentável, trabalhando com seus funcionários e suas famílias, a comunidade local e a sociedade em geral para melhorar a sua qualidade de vida (Almeida, 2002).

Porter e Kramer (2006) ao utilizar o termo responsabilidade social corporativa (RSC) voltam às atenções para um foco mais estratégico. Afirmam que existem quatro principais argumentos que motivam a adoção de uma gestão voltada para a RSC nas organizações, sendo estes: o apelo ou dever moral, a sustentabilidade, a licença para operar e a reputação. $\mathrm{O}$ dever moral se relaciona com "fazer a coisa certa", ou seja, a organização precisa agir conforme valores considerados corretos pela sociedade. A sustentabilidade se traduz na eficiência operacional de forma que não se comprometa os recursos existentes para as gerações futuras. A "licença para operar" retrata a aceitação das operações da empresa pelos stakeholders. Por último a reputação, liga a RSC à imagem da organização, fortalecimento da marca e valorização das ações. Os autores defendem que as questões de responsabilidade social, vislumbradas de forma estratégica, tendem a proporcionar grande avanço social, porque a organização aplica seus recursos em questões que a sociedade necessita. Com esta mesma visão, alguns autores inferem a necessidade da inclusão da variável sustentabilidade ao planejamento estratégico como Nascimento, Lemos e Mello (2008) e Tachizawa (2005).

A sustentabilidade corporativa vem adquirindo cada vez mais importância, uma vez que muitos estudos enfatizam a obtenção de vantagens competitivas pelas organizações a partir da preocupação e incorporação de práticas sustentáveis nas suas estratégias de gestão. Esta premissa é confirmada a partir de diversos estudos tais como, os de Hart e Milstein (2004), que consideram que a gestão pautada sob o conceito de desenvolvimento sustentável proporciona geração de valor ao acionista, a partir da redução dos níveis de consumo de matéria-prima e de poluição, operação com níveis mais amplos de transparência e responsabilidade, desenvolvimento de novas e 
revolucionárias tecnologias a fim de reduzir as pegadas do homem sobre o planeta e ainda atender as necessidades dos mais necessitados.

Outro trabalho desenvolvido por Hansen, Grosse-Dunker e Reichwald (2009) enfatiza que a inovação tecnológica sustentável conserva ou aumenta o capital global (econômico, ambiental e social) organizacional. Corroborando Quadros e Vilha (2006) defendem que a utilização de estratégias e práticas inovativas é capaz de gerar vantagens competitivas sustentáveis em relação a seus concorrentes. Ceretta et. al. (2009) ao analisar o balanço social cinquenta e nove (59) empresas que operam no Brasil identificaram uma relação positiva entre investimentos socioambientais e a performance financeira empresarial. Também Daroit e Nascimento (2004), salientam que a utilização de programas voltados para a sustentabilidade privilegia a dimensão econômica, através do aumento da lucratividade da empresa e da diminuição dos custos operacionais.

\section{A INFLUÊNCIA DA GESTÃO SUSTENTÁVEL NO PROCESSO DE INOVAÇÃO DAS EMPRESAS}

A inovação foi introduzida como um conceito fundamental para a explicação do desenvolvimento econômico já no início do século XX por Schumpeter e, apesar de manter sua origem, o conceito evoluiu ao longo das últimas décadas adquirindo um escopo bem mais amplo (Muller Neto, 2005).

Segundo Schumpeter (1934), a inovação é definida como um processo caracterizado pela descontinuidade daquilo que está estabelecido. Podendo ser concebida através da introdução de um novo bem ou nova qualidade de um bem, de um novo método de produção, da abertura de um novo mercado, da conquista de uma nova fonte de matéria-prima ou, ainda, da criação de uma nova forma de organização.

Para Kemp, Smith e Becher (2000) a literatura sobre inovação possui basicamente duas abordagens. A primeira analisa o comportamento do indivíduo inovador, partindo da premissa de que as empresas inovam através de oportunidades tecnológicas e a inovação se desenvolve onde ocorrem essas oportunidades. Já a segunda abordagem, considera a inovação a partir de uma concepção sistêmica de interações complexas entre a empresa e o ambiente. Essas relações com o entorno se dão em duas instâncias: relações entre empresas (dentro da cadeia produtiva) e as relações entre empresas e todo o ambiente econômico-social e institucional. O cerne dessa teoria enfatiza que o ambiente em que as organizações estão inseridas influencia a atitude das empresas com relação à inovação e o modo como a mesma ocorre.

De acordo com Kemp, Smith e Becher (2000), a inovação consiste em um fenômeno multifacetado, caracterizado por uma complexidade de inter-relações entre pessoas e instituições. Enfatizam que a inovação envolve de um lado, novas ideias e resoluções de problemas, podendo ser vista em termos de criatividade e esforço intelectual. E de outro, recursos financeiros e materiais, usualmente em larga proporção e em condições incertas, com elevado risco.

Segundo Damanpour (1991), a inovação pode ser um novo produto ou serviço, uma nova tecnologia de processo de produção, um novo sistema administrativo ou uma nova estrutura organizacional, ou ainda um novo plano ou programa. A inovação quando relacionada especificamente aos produtos, serviços e a tecnologia dos processos de produção é definida por este autor como inovação tecnológica.

O Manual de Oslo (OCDE, 2005), define inovação tecnológica como a introdução de produtos ou processos tecnologicamente novos e melhorias significativas em produtos e processos existentes. Para Porter (1992), a inovação tecnológica apresenta um papel importante no sucesso ou no fracasso de uma organização, pois têm significativas implicações estratégicas para as empresas e podem influenciar a indústria como um todo.

Na visão de Daroit e Nascimento (2004), a inovação está comumente associada ao enfoque econômico, sendo tratada apenas como forma de obtenção de lucros extras pelas empresas, por

Revista de Gestão Social e Ambiental - RGSA, São Paulo, v. 5, n. 2, p. 96-111, mai./ago. 2011. 
meio de vantagens competitivas decorrentes da produção de novos produtos ou processos que agregam valor para o cliente. No entanto, estes autores enfatizam que é preciso uma maior compreensão por parte das organizações sobre o papel da inovação com relação a seus efeitos sobre a sociedade e o meio ambiente.

Segundo Almeida (2007), o paradigma do desenvolvimento sustentável traz para as empresas dois grandes desafios: o primeiro consiste em gerar inovações necessárias à existência sustentável dos seres vivos, disponibilizando soluções tecnológicas capazes de desempenhar múltiplas funções; o outro está em vencer resistências da sociedade quanto aos novos produtos e serviços, particularmente sua descrença em relação a novas soluções frente às evidências da insustentabilidade dos sistemas produtivos e das atuais soluções tecnológicas incorporadas nos produtos e serviços que estão no mercado.

Neste sentido, Hall e Vredenburg (2003) colocam que a inovação tecnológica sustentável, orienta-se para o mercado a partir da incorporação dos princípios do desenvolvimento sustentável e requer tanto a incorporação das restrições oriundas das pressões sociais e ambientais, como a incorporação de uma visão que leve em consideração também as futuras gerações, ou seja, a perspectiva de longo prazo.

Investimentos em soluções de tecnologia limpa implicam na tendência empresarial de buscar abordagens mais inovadoras para os desafios de longo prazo e criar ambientes organizacionais que apóiam o processo de inovação. As empresas que forem capazes de desenvolver tecnologias revolucionárias que se propõem à satisfação das necessidades da sociedade estarão na direção do futuro crescimento econômico (Hart \& Milstein, 2004). Dessa forma, a inovação orientada para a sustentabilidade, definida por Hansen, Grosse-Dunker e Reichwald (2009), como uma ferramenta que permite abranger tanto as questões de sustentabilidade como também conquistar novos segmentos de clientes e mercados, constitui na inovação individualmente percebida por agregar valor positivo para o capital global da firma, sendo considerada como crítica para o crescimento sustentado e a prosperidade das organizações.

A fim de avaliar e estruturar os efeitos de inovações sustentáveis, Hansen, Grosse-Dunker e Reichwald (2009), propõe um modelo genérico denominado "cubo da inovação sustentável". Os autores, a partir da estruturação da literatura sobre inovação orientada para a sustentabilidade, desenvolvem o modelo em função de três dimensões inter-relacionadas, que são: a) dimensão alvo: explora o conceito de triple bottom line diferenciando os efeitos econômicos, ambientais e sociais; b) dimensão do ciclo de vida: abrange os efeitos de produtos e tecnologias dentro das diferentes fases de seus ciclos de vida; e c) dimensão dos tipos de inovação: avalia o potencial de inovações sustentáveis transcendendo o nível tecnológico para maiores contingentes de serviço.

A partir deste aporte teórico, o presente estudo identifica como as empresas do setor químico brasileiro gerenciam as práticas de inovação orientada para a sustentabilidade. Na próxima seção será descrito o método utilizado nesta pesquisa.

\section{MÉTODO DE PESQUISA}

\subsection{Tipo de pesquisa}

A pesquisa é caracterizada como um estudo de caso de natureza qualitativa e descritiva. $\mathrm{O}$ estudo de caso é definido por Yin (1990) como uma estratégia de pesquisa para o estudo de fenômenos sociais complexos, permitindo obter suas características e alcançar o objetivo da pesquisa. $\mathrm{O}$ autor ainda apresenta duas estratégias de estudo de caso: caso único ou casos múltiplos. Neste artigo, caracterizado como de casos múltiplos, foram obtidos dados e analisadas três empresas do setor químico que têm se destacado pela adoção de práticas voltadas à inovação e à sustentabilidade, buscando identificar como têm sido gerenciadas as práticas de inovação orientadas para a sustentabilidade.

Revista de Gestão Social e Ambiental - RGSA, São Paulo, v. 5, n. 2, p. 96-111, mai./ago. 2011. 


\subsection{Procedimentos para coleta e análise dos dados}

Os dados obtidos foram coletados a partir de entrevistas semiabertas, realizadas durante o primeiro semestre de 2010, com os principais executivos de pesquisa e desenvolvimento de três empresas químicas que produzem sabões, detergentes, produtos de limpeza, cosméticos, perfumaria e higiene pessoal. Outras informações foram coletadas nos web sites e relatórios anuais e de sustentabilidade divulgados pelas empresas.

A análise dos dados foi efetuada de forma descritiva através do método de análise de conteúdo, que de acordo com Bardin (1977, p. 46), trata da "manipulação de mensagens para evidenciar os indicadores que permitam inferir sobre uma realidade que não é a mensagem". Os dados foram analisados e organizados em função das orientações do modelo, que propõe que para a existência de inovação sustentável as empresas precisam agir de acordo com as cinco dimensões descritas no modelo conceitual a seguir.

\subsection{Modelo conceitual da pesquisa}

O modelo conceitual do trabalho foi adaptado de Hansen, Grosse-Dunker e Reichwald (2009) que a partir das três dimensões do modelo genérico: dimensão alvo, do ciclo de vida e dos tipos de inovação, identificaram implicações práticas para a gestão da inovação sustentável, representada através das categorias: integração do critério da sustentabilidade; integração de stakeholders e usuários; ampliação do sistema de produto-serviço; marketing da sustentabilidade direcionado para a inovação sustentável; e sensibilização no contexto da sustentabilidade. De acordo com Hansen, Grosse-Dunker e Reichwald (2009), as categorias identificadas como implicações práticas para a gestão da inovação sustentável, são a seguir descritas.

A integração do critério da sustentabilidade se aplica ao potencial de sustentabilidade das inovações. Os critérios de sustentabilidade devem ser integrados no processo de inovação para orientar o desenvolvimento e a criação de inovações que asseguram o envolvimento de critérios sociais e ambientais ao longo do caminho do processo de produção. Está relacionado diretamente à avaliação do impacto potencial do processo ou do produto no capital natural ou humano.

A integração de stakeholders e usuários relaciona-se à integração dos stakeholders na tomada de decisões sobre o desenvolvimento de novos produtos ou processos. Através do envolvimento de clientes na busca de oportunidades de negócios para os produtos existentes; de parcerias com organizações e institutos, na formação de parcerias para impulsionar as iniciativas de sustentabilidade; e envolvimento dos empregados, incentivando os colaboradores a participar de atividades que visam o desenvolvimento sustentável através de uma combinação de comunicação interna e formação em iniciativas de sustentabilidade.

A ampliação do sistema de produto-serviço (Product-Service System - PSS) está relacionada ao desenvolvimento de alternativas à compra direta de produtos. Partindo da ideia de que os consumidores não comprem o produto em si, mas sim a utilidade que estes produtos e serviços oferecem, buscando novos caminhos para a gestão da inovação que contribuam diretamente na tomada de decisão. Ainda é possível que as empresas desenvolvam outras atividades como leasing de produtos ou produção por demanda.

O marketing da sustentabilidade direcionado para a inovação sustentável foca na criação e projeção de novas necessidades sustentáveis que possam mudar o curso dos atuais estilos de vida, a fim de melhor desenvolver os serviços de produtos e modelos de negócios. Sendo assim, a gestão da inovação será cada vez mais desafiada a criar e projetar novas necessidades sustentáveis de modo a alterar curso dos atuais estilos de vida. O marketing da sustentabilidade constitui um dos principais motores da inovação tecnológica sustentável, pois aumenta a possibilidade de sucesso das inovações no mercado, ilustrando uma ferramenta crucial para a gestão da inovação. Ações que buscam desenvolver essa dimensão são: análise do comportamento do consumidor, comunicação da vantagem sócio-ecológica dos produtos sustentáveis e incentivo ao consumo sustentável.

Revista de Gestão Social e Ambiental - RGSA, São Paulo, v. 5, n. 2, p. 96-111, mai./ago. 2011. 
A sensibilização no contexto da sustentabilidade pode levar a uma redução dos riscos direcionais de inovações sustentáveis. Quanto mais os decisores estão sensibilizados, melhor se pode identificar e avaliar potenciais de sustentabilidade dos diferentes pontos de vista referente aos importantes grupos de stakeholders. Isso pode ser conseguido através da compreensão e interatividade dos conceitos de sustentabilidade.

Dessa forma, o esquema conceitual que orientará o presente estudo, terá como base as categorias identificadas como implicações práticas para a gestão da inovação sustentável por Hansen, Grosse-Dunker e Reichwald (2009), conforme Figura 1.

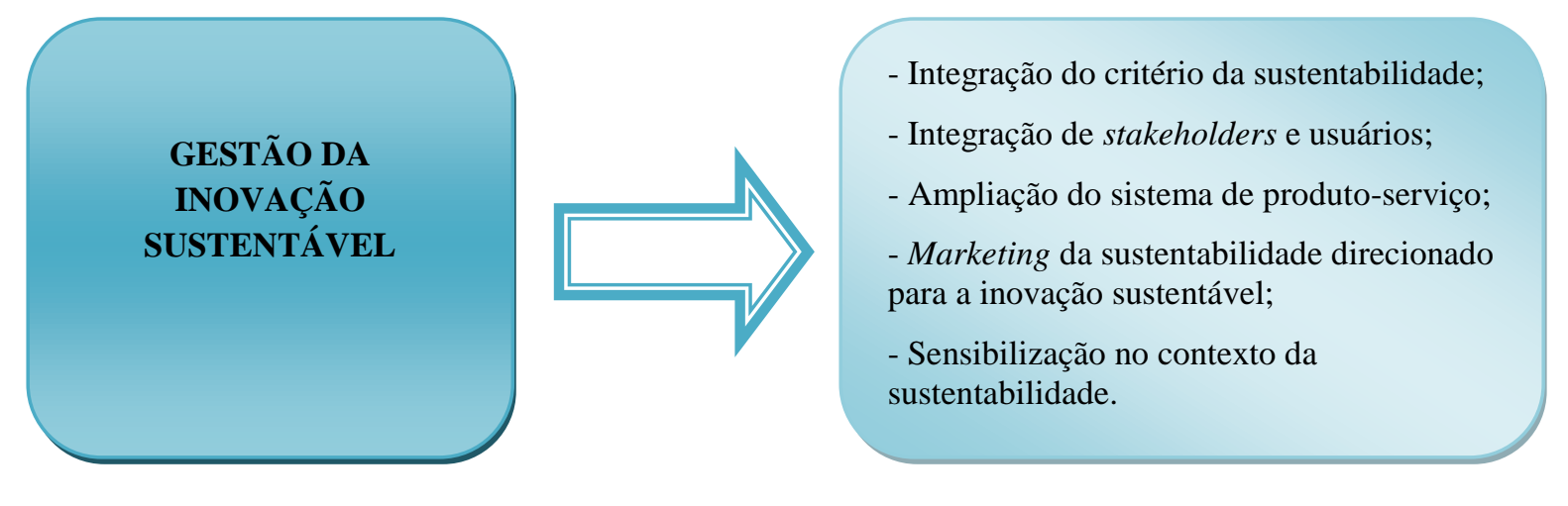

Figura 1: Modelo conceitual do estudo.

Fonte: Adaptado a partir de Hansen, Grosse-Dunker e Reichwald (2009).

Com base no referencial teórico foi desenvolvido o pressuposto central do estudo:

As empresas analisadas buscam agregar valor ao produto e ao processo por meio de práticas de inovação orientadas para a sustentabilidade.

\section{ANÁLISE E DISCUSSÃO DOS RESULTADOS}

Os resultados estão apresentando em categorias conforme os cinco aspectos definidos pelo modelo de Hansen, Grosse-Dunker e Reichwald (2009): integração do critério da sustentabilidade, integração de stakeholders e usuários, ampliação do sistema de produto-serviço, marketing da sustentabilidade direcionado para a inovação sustentável e sensibilização no contexto da sustentabilidade.

\subsection{Caracterização das empresas}

As empresas estudadas fazem parte do segmento da indústria química de sabões, detergentes, produtos de limpeza, cosméticos, perfumaria e higiene pessoal do setor químico. Essas empresas foram selecionadas pela abrangência nacional e internacional de seus produtos e pelo grande investimento em inovações.

A Empresa A é a maior rede de franquias de perfumaria e cosméticos do mundo com mais de 600 produtos no seu portfólio (perfumaria, cremes, loções e maquiagem). Possui mais de 2.800 lojas no Brasil e lojas exclusivas em 13 países. Tem mais de 1.400 colaboradores diretos, 915 franqueados e gera mais de 14 mil empregos na rede. Seu principal tipo de inovação é em produto e processo. Possui programas que visam a sustentabilidade de suas operações como, por exemplo, de eco-eficiência.

A Empresa $B$ é uma das maiores afiliadas do grupo fora dos Estados Unidos empregando 115 mil pessoas no mundo todo. Como oferece uma gama de produtos, a empresa se separa em produtos diretos para o consumidor (higiene e saúde pessoal e cosméticos), produtos farmacêuticos (remédios e de uso hospitalar) e produtos médicos (dispositivos médicos e de diagnósticos). Pela 
característica do setor que está sendo avaliado foi pesquisada somente a empresa que oferece produtos diretamente ao consumidor. Possui um centro de pesquisas e tecnologia que supre o mercado latino-americano na busca de novos métodos e processos de fabricação de produtos. Também participa ativamente de projetos sociais em sua comunidade, estimulando seus colaboradores a participarem das campanhas da empresa.

A Empresa $C$ é fornecedor líder no mundo de soluções comerciais que combinam química, máquinas, utensílios, administração e distribuição, embalagem e processos para otimizar os resultados ao reduzir o desperdício, a água e o consumo de energia e proteção dos trabalhadores. Surgiu originalmente nos Estados Unidos e tem filiais em mais de 60 localidades como Europa, África, Ásia e no Continente Americano, empregando 10.400 pessoas no mundo. A organização mantém projetos para orientar crianças do mundo todo quanto a saúde e higiene, em busca de melhor qualidade de vida.

A seguir apresenta-se no Quadro 1 a caracterização dos entrevistados em cada uma das três indústrias. Foram entrevistadas pessoas com conhecimento e experiência na área de inovação, para fins de obter respostas mais alinhadas ao objetivo do estudo.

\begin{tabular}{c|c|c|c|c}
\hline Empresa & Respondente & Formação & $\begin{array}{c}\text { Tempo de } \\
\text { empresa }\end{array}$ & $\begin{array}{c}\text { Funcionários sob sua a } \\
\text { responsabilidade }\end{array}$ \\
\hline A & $\begin{array}{c}\text { Diretor de Pesquisa e } \\
\text { Inovação }\end{array}$ & $\begin{array}{c}\text { Farmacêutico- } \\
\text { Bioquímico }\end{array}$ & 11 anos & 27 \\
\hline B & $\begin{array}{c}\text { Diretora de P\&D e } \\
\text { Inovação }\end{array}$ & Engenheira Química & 4,5 anos & 25 \\
\hline C & Diretora de P\&D & Engenheira Química & 33 anos & 32 \\
\hline
\end{tabular}

Quadro 1: Caracterização dos respondentes.

Fonte: Dados da pesquisa.

\subsection{Integração do critério da sustentabilidade}

A integração dos aspectos sociais e ambientais no desenvolvimento dos produtos ou processos faz parte da estratégia organizacional das empresas analisadas. A preocupação com a avaliação do impacto potencial dessas inovações tecnológicas no capital natural é constante, bem como avaliações das substâncias utilizadas para que não prejudiquem a saúde das pessoas. Por isso, investimentos em práticas de reciclagem de resíduos sólidos, redução dos gases de efeito estufa, eficiência energética, redução do consumo de água, redução de poluição ambiental por descarte das embalagens, análise do ciclo de vida dos produtos (ACV), melhorias na qualidade e segurança no local trabalho são frequentes nas empresas estudadas.

A Empresa $A$ investe na redução dos impactos sociais e ambientais nos processos e produtos, destacando-se que a mesma possui programas que visam a sustentabilidade de suas operações como, por exemplo, de eco-eficiência.

O setor químico tem restrições ao uso de qualquer substância indiscriminadamente, conforme afirmação da diretora de P\&D da Empresa $C$ existe uma lista de produtos e materiais chamada de red list que contém materiais proibidos de serem utilizados nas formulações. Esta lista é muito mais rigorosa que a lista de materiais não permitidos pelo Ministério da Saúde. Além disso, disponibilizam os produtos em embalagens seguras e com sistema de dosagem que evita o contato físico com os usuários. Uma linha completa de limpeza desta empresa possui certificação de produto ambientalmente responsável com menor impacto e menor emissão de odores no ambiente. Outro aspecto importante a ser realçado nesta organização é o investimento em tecnologia da informação, uma vez que seus sistemas de informação estão programados para reações efetivas em momentos de algum risco iminente. 
Para a Empresa $B$ os primeiros aspectos considerados no desenvolvimento de novos produtos e processos são as oportunidades de mercado, alguma necessidade do consumidor (não sustentável) ou reação a alguma ação da concorrência. Depois de identificado o tipo de produto que precisa ser desenvolvido, são feitos os testes para identificar a possibilidade de impacto social e ambiental. Diversos testes toxicológicos são feitos para que os produtos não afetem a saúde humana ou poluam o ambiente. A empresa também investe na avaliação dos produtos antes e após seu lançamento no mercado e no gerenciamento de recursos, feito principalmente no que se refere ao desenvolvimento das embalagens. Ações como redução do tamanho e do peso das embalagens, reciclagem dessas embalagens pós-consumo e utilização de materiais biodegradáveis buscam a redução dos impactos gerados pela utilização dos produtos. Trabalhando com metas para reduzir ainda mais o consumo de materiais como o PVC (cloreto de polivinila) utilizado em embalagens, selos e invólucros de seus produtos.

\subsection{Integração de stakeholders e usuários}

A integração de stakeholders nas decisões sobre o desenvolvimento de novos produtos ou processos faz parte da inovação em algumas das organizações foco do estudo, como por exemplo, o relacionamento com universidades em busca de novas tecnologias. No caso da Empresa $A$ uma parceria com a Unicamp substituiu gordura animal, pela vegetal em uma técnica de extração de óleos essenciais de flores.

$\mathrm{O}$ investimento em relacionamentos com fornecedores e franqueados no processo de logística de fluxos de retorno têm dado resultado para a Empresa A. Pois através de ações como oficinas de capacitação e reconhecimento de melhores práticas ambientais, para ampliar a inserção da sustentabilidade na cadeia de abastecimento, têm contribuído para a melhoria contínua do negócio.

A Empresa $B$ investe no relacionamento com clientes para identificar a aceitação dos produtos no mercado; com a comunidade desenvolve campanhas que visam informar as pessoas sobre os cuidados necessários com a saúde; com os colaboradores busca entender qualquer tipo de problemas que tenham a relatar; e com os acionistas buscam sugestões. Mantém relacionamento com a comunidade médica, pois muitos dos produtos são farmacêuticos. Realizam benchmarking periodicamente com competidores de igual importância, monitorando a ciência, regulamentações e questões emergentes. Dessa forma, embora tenha sido possível verificar o envolvimento da empresa com os seus diversos stakeholders e usuários, essa preocupação não ocorre na fase de desenvolvimento do produto ou processo e sim posteriormente, isto é, após o desenvolvimento da tecnologia e/ou lançamento do produto.

Parcerias com órgãos governamentais e não governamentais constitui prática constante da Empresa $C$, com o intuito de melhorar a eficiência energética e reduzir as emissões de gases de efeito estufa no que se refere ao processo produtivo da empresa. Além disso, proporciona maior participação de seus colaboradores por meio da oportunidade e responsabilidade de sugerir melhorias no processo de produção.

Para a Empresa $C$ a prática de relacionamento com clientes também é importante, pois muitas sugestões sobre novos produtos são recebidas pela empresa por meio do web site, em um campo específico. Um centro de inovação e aprendizagem em Xangai, especificamente para os clientes, permite trocas de experiências e maior integração com os mesmos. Como o desenvolvimento de um mix de produtos voltados especialmente para uma rede mundial de hotéis, que proporcionou a criação de uma espuma utilizada para lavar as mãos, que resulta em duas vezes menos resíduos.

Revista de Gestão Social e Ambiental - RGSA, São Paulo, v. 5, n. 2, p. 96-111, mai./ago. 2011. 


\subsection{Ampliação do sistema de produto-serviço}

O conceito do sistema de ampliação de produto-serviço não é novo, mas ainda não está totalmente difundido nas empresas, uma vez que não pôde ser evidenciado em sua totalidade em nenhuma das organizações analisadas.

Na Empresa $C$, a diretora de P\&D argumenta que alguns projetos de inovações utilizam o conceito de substituição de produtos químicos por alternativas inovadoras como, por exemplo, água eletrolisada, mas esse resultado trata de uma inovação tecnológica e não de uma substituição de um produto por um serviço.

A Empresa $A$ apresenta um sistema de canais reversos de distribuição que buscam solucionar o problema da quantidade de produtos descartados no meio ambiente por meio da logística de fluxos de retorno que executa a recuperação de produtos, reintegrando-os aos ciclos produtivos e de negócios. Essas atividades são desenvolvidas em conjunto com alguns stakeholders, como fornecedores e franqueados. A empresa também possui embalagens refiláveis em que o consumidor compra somente o refil. Dessa forma, a empresa tem buscado soluções de menor impacto econômico, ecológico e até emocional, na medida em que seus clientes se sentem menos culpados pelos estragos que o seu consumo possa causar ao meio ambiente. Embora tenha sido possível identificar na Empresa A, aspectos que tangenciam a variável ampliação do sistema de produto-serviço, não foi possível identificar o seu desenvolvimento na íntegra.

$\mathrm{Na}$ Empresa B não foi possível identificar nenhum tipo de política relacionada a variável ampliação do sistema de produto-serviço (Product-Service System-PSS).

\subsection{Marketing da sustentabilidade direcionado para a inovação sustentável}

O marketing da sustentabilidade direcionado para a inovação sustentável foca na criação e projeção de novas necessidades sustentáveis que possam mudar o curso dos atuais estilos de vida. Neste sentido, a diretora de P\&D da Empresa $C$ enfatiza que criar a necessidade de produtos sustentáveis nos clientes/consumidores faz parte da estratégia de negócios da empresa, ressaltando que esta investe na divulgação das vantagens dos produtos com apelo ecológico para os clientes/consumidores de forma intensiva. Destaca-se que a empresa possui uma ampla gama de produtos certificados ecologicamente pelo Rótulo Ecológico Europeu e que novos produtos e melhorias em produtos existentes, podem ser desenvolvidos a partir de ideias de clientes por meio de um canal exclusivo no web site da empresa.

Na Empresa $B$ a diretora de P\&D resgatou o lançamento de uma escova dental ecológica, em que o cabo foi feito com $40 \%$ de materiais que seriam descartados pela empresa, vendida por um preço acessível ao consumidor, incentivando, dessa forma, a reflexão da comunidade sobre o consumo de produtos com menor impacto ao ambiente. Porém, destaca-se que esta ação não foi desenvolvida de forma a criar necessidades sustentáveis nos clientes, e sim a partir de uma oportunidade identificada pela empresa, já que foi possível constatar que o surgimento de novos produtos pode originar-se basicamente de três modos: através de idéias e sugestões de consumidores; por meio de necessidades da sociedade detectadas pelo centro de pesquisa e tecnologia; ou através de novas tecnologias que permitem aplicar melhoramentos aos produtos já existentes. Destaca-se que a empresa também trabalha com a avaliação dos produtos pelos consumidores, mensurando sua satisfação com os mesmos, através de mecanismos como surveys, interação pelo web site e grupos focais.

A Empresa A procura conhecer as opiniões dos consumidores, através de diversos canais, e afirma acompanhar as demandas de mercado. A empresa também alega que a sustentabilidade dos negócios não está somente no desenvolvimento de linhas de produtos sustentáveis, mas na integração desses critérios em toda a cadeia de produção. Destaca-se a criação em 2006 pela empresa, de um programa que incentiva a reciclagem das embalagens por parte dos consumidores. As lojas de produtos contam com coletores e materiais informativos que reforçam a iniciativa. Após

Revista de Gestão Social e Ambiental - RGSA, São Paulo, v. 5, n. 2, p. 96-111, mai./ago. 2011. 
o recolhimento, o material é encaminhado aos parceiros locais para a descaracterização e reciclagem, permitindo, dessa forma, a utilização do resíduo como matéria-prima.

\subsection{Sensibilização no contexto da sustentabilidade}

O conceito de sustentabilidade se apresenta de forma difundida entre os entrevistados, há consciência da importância da sustentabilidade nas operações e o tema é considerado pelas lideranças, através do reconhecimento de que o desempenho econômico pode ser afetado pelo ambiente econômico, ambiental, social, político e financeiro.

Na Empresa A é possível identificar um modelo de gestão da sustentabilidade que envolve os diferentes níveis hierárquicos da empresa na definição de diretrizes e responsabilidades claras para cada área envolvida. Seus valores e políticas são pautados pelos conceitos de sustentabilidade. Pois, conforme afirmação do diretor de $\mathrm{P} \& \mathrm{D}$, a sustentabilidade é um valor forte no grupo e presente em todas as decisões. Por isso, investe esforços na integração stakeholders para criar valor e gerar resultados positivos para a sociedade.

Na Empresa $B$ a própria presidente da empresa lidera um canal de news letters em que são veiculadas informações sobre o que a empresa faz, informações sobre as ações dos concorrentes, sobre sustentabilidade e desenvolvimento de produtos e que acaba por influenciar pessoas nessas questões.

Para a Empresa $C$ as metas na diminuição de emissões de gases do efeito estufa (GEE) fazem parte das metas dos diretores, que apresentam suas remunerações atreladas às metas de redução de emissões da empresa.

Com base na análise sobre a gestão da inovação sustentável das empresas estudadas pode-se destacar algumas características importantes, apresentadas no Quadro 2.

\begin{tabular}{|c|c|c|c|}
\hline Variáveis & Empresa A & Empresa B & Empresa C \\
\hline $\begin{array}{l}\text { Integração do } \\
\text { critério da } \\
\text { sustentabilidade }\end{array}$ & $\begin{array}{l}\text { - Investimentos em na redução } \\
\text { dos impactos sociais e } \\
\text { ambientais nos processos e } \\
\text { produtos. }\end{array}$ & $\begin{array}{l}\text { - Investimentos em } \\
\text { eco-eficiência no } \\
\text { processo e produto; } \\
\text { - Investimentos na } \\
\text { redução dos materiais } \\
\text { usados nas } \\
\text { embalagens. }\end{array}$ & $\begin{array}{l}\text { - Certificação de produto } \\
\text { ambientalmente; } \\
\text { - Investimentos na redução } \\
\text { dos materiais usados nas } \\
\text { embalagens; } \\
\text { - Produtos em embalagens } \\
\text { com sistema de dosagem; } \\
\text { - Red List. }\end{array}$ \\
\hline $\begin{array}{l}\text { Integração de } \\
\text { stakeholders e } \\
\text { usuários }\end{array}$ & $\begin{array}{l}\text { - Parcerias com universidade } \\
\text { para geração de tecnologia; } \\
\text { - Relacionamentos com } \\
\text { fornecedores e franqueados } \\
\text { no processo de logística de } \\
\text { fluxos de retorno. }\end{array}$ & $\begin{array}{l}\text { Relacionamentos com } \\
\text { clientes, comunidade, } \\
\text { universidades, } \\
\text { colaboradores, } \\
\text { acionistas e } \\
\text { benchmarking com } \\
\text { competidores, porém } \\
\text { na fase posterior ao } \\
\text { desenvolvimento. }\end{array}$ & $\begin{array}{l}\text { - Relacionamento com } \\
\text { clientes (web site) e } \\
\text { colaboradores; } \\
\text { - Parcerias com órgãos } \\
\text { governamentais e não } \\
\text { governamentais; } \\
\text { - Centro de Inovação em } \\
\text { Xangai. }\end{array}$ \\
\hline $\begin{array}{l}\text { Ampliação do } \\
\text { sistema de } \\
\text { produto-serviço } \\
\end{array}$ & $\begin{array}{l}\text { - Sistema de Canais reversos de } \\
\text { distribuição; } \\
\text { - Embalagens refiláveis. }\end{array}$ & - Não pratica & - Não pratica \\
\hline $\begin{array}{l}\text { Marketing da } \\
\text { sustentabilidade } \\
\text { direcionado para } \\
\text { a inovação } \\
\text { sustentável }\end{array}$ & $\begin{array}{l}\text { - Utilização de diversos canais } \\
\text { de comunicação para } \\
\text { acompanhar as demandas de } \\
\text { mercado; } \\
\text { - Sustentabilidade na cadeia } \\
\text { produtiva da empresa. }\end{array}$ & $\begin{array}{l}\text { - Análise das } \\
\text { necessidades e } \\
\text { avaliação dos } \\
\text { produtos pelos } \\
\text { consumidores por } \\
\text { diversos canais; } \\
\text { - Desenvolvem }\end{array}$ & $\begin{array}{l}\text { - Divulgação da vantagem } \\
\text { sócio-ecológica dos } \\
\text { produtos; } \\
\text { - Diagnóstico das } \\
\text { necessidades dos } \\
\text { clientes/consumidores por } \\
\text { meio de canais como web }\end{array}$ \\
\hline
\end{tabular}

Revista de Gestão Social e Ambiental - RGSA, São Paulo, v. 5, n. 2, p. 96-111, mai./ago. 2011. 


\begin{tabular}{|c|c|c|c|}
\hline & & $\begin{array}{l}\text { produtos com apelo } \\
\text { sustentável }\end{array}$ & site e treinamentos. \\
\hline $\begin{array}{l}\text { Sensibilização no } \\
\text { contexto da } \\
\text { sustentabilidade }\end{array}$ & $\begin{array}{l}\text { Envolve todos os níveis } \\
\text { hierárquicos da empresa na } \\
\text { definição das diretrizes e } \\
\text { responsabilidades claras para } \\
\text { cada área envolvida. }\end{array}$ & $\begin{array}{l}\text { - O presidente da } \\
\text { empresa lidera um } \\
\text { canal de news letters. }\end{array}$ & $\begin{array}{l}\text { - Engajamentos das metas } \\
\text { dos diretores, que } \\
\text { apresentam suas } \\
\text { remunerações atreladas às } \\
\text { metas de redução de } \\
\text { emissões de GEE da } \\
\text { empresa. }\end{array}$ \\
\hline
\end{tabular}

\section{Quadro 2: Resumo das categorias dos resultados.}

Fonte: Dados da pesquisa.

Os resultados corroboram com o pressuposto inicialmente formulado, ao evidenciar que as empresas têm buscado investir em desenvolvimento de novos produtos e melhorias de produtos e processos de forma sustentável.

\section{CONSIDERAÇÕES FINAIS}

A inovação orientada para a sustentabilidade permite abranger tanto as questões de sustentabilidade, como também conquistar novos segmentos de clientes e mercados, consistindo na inovação individualmente percebida por agregar valor positivo para o capital global da firma (Hansen, Grosse-Dunker e Reichwald, 2009). Dessa forma, através da adaptação do modelo conceitual desenvolvido por Hansen, Grosse-Dunker e Reichwald (2009), este estudo buscou identificar como as empresas do setor químico brasileiro gerenciam as práticas de inovação orientadas para a sustentabilidade, por meio da análise das seguintes dimensões: integração do critério da sustentabilidade, integração de stakeholders e usuários, ampliação do sistema de produto-serviço, marketing da sustentabilidade direcionado para a inovação sustentável e sensibilização no contexto da sustentabilidade.

No que se refere a dimensão integração do critério da sustentabilidade, foi possível identificar que a integração dos aspectos sociais e ambientais no desenvolvimento dos produtos ou processos, faz parte da estratégia organizacional das empresas analisadas. A preocupação com a avaliação do impacto potencial dessas inovações tecnológicas no capital natural é constante, bem como avaliações das substâncias utilizadas para que não prejudiquem a saúde das pessoas. Dessa forma, pode-se dizer que as empresas analisadas estão contribuindo para a construção de um futuro sustentável, já que segundo Leal (2009) essa construção no contexto organizacional depende rigorosamente do estabelecimento de mudanças corporativas e da adoção de práticas gerenciais transparentes que valorizem as dimensões sociais e ambientais, melhorando a qualidade de vida, o bem-estar social, o equilíbrio econômico entre as nações e o respeito ao meio ambiente.

Quanto à integração de stakeholders e usuários na tomada de decisões sobre o desenvolvimento de novos produtos ou processos, constatou-se que este critério faz parte da inovação em algumas das organizações foco do estudo através de parcerias com universidades, com clientes, fornecedores, organizações não governamentais, entre outros parceiros. Corroborando com a literatura estudada, que apresenta o processo de inovação como um fenômeno complexo e interrelacionado com pessoas e instituições (Kemp, Smith, \& Becher, 2000). Destaca-se que com relação a esta dimensão, embora tenha sido possível verificar o envolvimento da Empresa B com os seus diversos stakeholders e usuários, essa preocupação não ocorre na fase de desenvolvimento do produto ou processo e sim posteriormente, isto é, após o desenvolvimento da tecnologia e/ou lançamento do produto.

Revista de Gestão Social e Ambiental - RGSA, São Paulo, v. 5, n. 2, p. 96-111, mai./ago. 2011. 
A ampliação do sistema de produto-serviço ainda consiste em um desafio para as empresas, uma vez que esse tipo de estratégia não tem seu conceito plenamente entendido e ainda não é foco das ações das empresas analisadas. Para Manzini e Vezzoli (2003) a adoção de um modelo de negócios baseado em um sistema de serviço de produto-serviço é interessante, pois implica em novos tipos de relacionamentos entre stakeholders e parceiros, além do surgimento de novos interesses econômicos e, ainda, na otimização de recursos. Dessa forma, esse critério representa uma oportunidade a ser explorada pelas empresas pesquisadas, a fim de otimizar recursos e agregar valor aos consumidores a partir da substituição de produtos por serviços.

As ações de marketing direcionadas para a inovação sustentável, em sua maioria, focam a criação e projeção de novas necessidades sustentáveis através da comunicação da vantagem sócioecológica dos produtos e comunicação com consumidor. Porém, destaca-se que na Empresa B as ações de marketing identificadas não foram desenvolvidas de forma a criar necessidades sustentáveis nos clientes, e sim a partir de uma oportunidade identificada pela empresa.

A última variável tratou da sensibilização no contexto da sustentabilidade, em que foi possível identificar a conscientização, por parte das lideranças, da importância da sustentabilidade nas operações e produtos das empresas. A integração da sustentabilidade ao longo processo produtivo das empresas, bem como o engajamento com os diversos stakeholders, demonstra o impacto que o tema da sustentabilidade possui na realidade empresarial e o quanto os esforços no desenvolvimento de práticas socioambientais podem contribuir para o sucesso dos negócios.

A partir de uma análise global de todos os critérios da gestão da inovação sustentável é possível confirmar o pressuposto que orientou a execução do estudo, afirmando que as empresas analisadas, de modo geral, buscam agregar valor ao produto e ao processo através do investimento em aspectos sustentáveis. Vale ressaltar que ainda existe oportunidade para a ampliação do sistema de produto-serviço por parte das empresas, de forma o integrar inovação e sustentabilidade agregando valor ao seu capital global, tendo em vista que não foi possível observar a execução deste critério em sua totalidade em nenhuma das organizações analisadas.

Também o estudo identificou oportunidades a serem desenvolvidas pela Empresa B. Com relação ao critério integração de stakeholders e usuários, a empresa precisa aperfeiçoar tais relacionamentos, de modo que os mesmos ocorram na fase de desenvolvimento do produto ou processo. E no que se refere a categoria marketing da sustentabilidade direcionado para a inovação sustentável, a empresa possui a oportunidade de desenvolver ações de forma a criar necessidades sustentáveis nos clientes.

\section{REFERÊNCIAS}

ABIQUIM - Associação Brasileira da Indústria Química. (2009). Recuperado em 29 novembro, 2009, de http://www.abiquim.org.br/.

Almeida, F.(2002). O bom negócio da sustentabilidade (1 ${ }^{\mathrm{a}}$ Ed.). Rio de Janeiro: Editora Nova Fronteira.

(2007). Os desafios da sustentabilidade. Rio de Janeiro: Elsevier.

Bardin, L.(1977). Análise de conteúdo. (7ª Ed). Lisboa: Edições.

Brito, E.Z.; Lombardi, M.S (2007, Setembro). Desenvolvimento sustentável como fator de competitividade. Anais do $31^{\circ}$ Encontro Nacional da ANPAD, Rio de Janeiro, RJ, Brasil, 22 a 26. 
Ceretta, P.S; Barba, F.G.; Casarin, F.; Kruel, M., \& Milani, B. (2009). Desempenho financeiro e a questão dos investimentos sócio-ambientais. Revista de Gestão Social e Ambiental, 3(3), 72-84.

CMMAD - Comissão Mundial Sobre Meio Ambiente E Desenvolvimento. Nosso futuro comum. Rio de Janeiro: Fundação Getúlio Vargas - FGV, 1991.

Damanpour, F. (1991). Organizational innovation: a meta-analysis of effects of determinants and moderators. Academy of Management Journal, 3 (34), 555-590.

Daroit, D., \& Nascimento, L. F. (2004, Setembro).Dimensões da inovação sob o paradigma do desenvolvimento sustentável. Anais $28^{\circ}$ Encontro Nacional da ANPAD, Curitiba, PR, Brasil, 25 a 29.

- (2000, setembro). A busca da qualidade ambiental como incentivo à produção de inovações. Anais do $24^{\circ}$ Encontro Nacional da ANPAD, Florianópolis, SC, Brasil.

Elkington, J. (2001). Canibais com garfo e faca. São Paulo: Makron Books.

Gomes, C.; Krugliankas, I.; Horneau Júnior, F., \& Scherer, F.(2009). Gestão da inovação tecnológica para o desenvolvimento sustentável em empresas internacionalizadas. Gestão \& Regionalidade, 25 (73), 35-47.

Hansen, E; Grosse-Dinker, F., \& Reichwald, R. (2009). Sustainability innovation cube: a framework to evaluate sustainability-oriented innovations. International Journal of Innovation Management, 13(4), 683-713.

Hall, J.,\& Vredenburg, H.(2003). The challenges of innovating for sustainable development. Mit Sloan Management Review, 45(1), 61-68.

Hart, S.L., \& Milstein; M.B. (2004). Criando valor sustentável. RAE Executivo, 3( 2), 66-79.

Hawken, P.; Lovins, A., \& Lovins, H. (2000). Capitalismo natural: criando a próxima revolução industrial. São Paulo: Cultrix - Amana-Key.

Kemp, R; Smith, K., \& Becher, G. (2000). How should we study the relationship between environmental regulation and innovation? Recuperado em 04 julho, 2010 de http://ftp.jrc.es/EURdoc/eur19827en.pdf

Leal, C.E.(2009). A era das organizações sustentáveis. Revista Eletrônica Novo Enfoque da Universidade Castelo Branco, 8 (8), 1-11. Recuperado em 5 maio, 2010, de http://www.castelobranco.br/sistema/novoenfoque

Lins, C., \& Wajnberg, D.(2007). Sustentabilidade corporativa no setor financeiro brasileiro. Rio de Janeiro: Fundação Brasileira para Desenvolvimento Sustentável.

Manzini, E., \& Vezzolli, C.(2002). O desenvolvimento de produtos sustentáveis: os requisitos ambientais dos produtos industriais. São Paulo: Editora da Universidade de São Paulo, 2002.

Mont, O.K.(2002). Clarifying the concept of product-service system. Journal of Cleaner Production, 10, (3), 237-245. 
Muller, H., Neto (2005). Inovação orientada para mercado: um estudo das relações entre orientação para mercado, inovação e performance. Tese de Doutorado, Universidade Federal do Rio Grande do Sul, Porto Alegre, RS, Brasil.

Nascimento, L.F.; Lemos, Â.D., \& Mello, M.C. (2008). Gestão socioambiental estratégica. Porto Alegre: Bookman.

OCDE. Manual de Oslo: diretrizes para coleta e interpretação de dados sobre inovação.

$3^{\text {a }}$ ed. FINEP: Rio de Janeiro, 2005.

Porter, M. E. (1992). Vantagem competitiva: criando e sustentando um desempenho superior (E. M. de P. Braga, Trad). Rio de Janeiro: Campus (Obra original publicada em 1990)

Porter, M., \& Kraemer, M.R. Strategy \& society: the link between competitive advantage and corporate social responsibility. Harvard Business Review, December 2006.

Quadros, R., \& Vilha, A. M.(2006). Tecnologias de Informação no Gerenciamento do Processo de Inovação. Revista Fonte, 3(6), 129-133.

Schumpeter, J.A.(1934). Capitalismo, socialismo e democracia. Rio de Janeiro: Fundo de Cultura.

Tachizawa, T.(2005). Gestão ambiental e responsabilidade social corporativa: estratégias de negócio focadas na realidade brasileira. ( $3^{\mathrm{a}}$ Ed). São Paulo: Atlas.

Teigland, R.; Fey, C., \& Birkinshaw, J. (2000). Knowledge dissemination in global R\&D operations. Management International Review, 40, (1), 49-77.

Scharf, R.(2004). Manual de negócios sustentáveis. São Paulo: Amigos da Terra.

Verfaillie, H.A., \& Bidwell, R. (2000). Medir a eco-eficiência: um guia para comunicar o desempenho da empresa. Recuperado em 10 junho, 2000, de http://www.wbcsd.org//printpdf/measuring.pdf.

WBCSD - World Business Council For Sustainable Development. Eco-efficiency: creating more value with less impact. WBCSD: Agosto, 2000. Recuperado em 13 junho, 2010, de http://www.wbcsd.ch/web/publications/eco_efficiency_creating_more_value.pdf

Yin, R.K.(2001). Estudo de caso: planejamento e métodos. $2^{\mathrm{a}}$ ed. Porto Alegre: Bookman.

Zanca, J.; Araujo, F.; Quelhas, O., \& Costa, H (2008, agosto). Responsabilidade social corporativa e comportamento organizacional: um paralelo de evolução. Anais do Congresso Nacional de excelência em gestão, Rio de Janeiro, RJ, Brasil, 31-02.

Data do recebimento do artigo: 22/03/2011

Data do aceite de publicação: 05/08/2011

Revista de Gestão Social e Ambiental - RGSA, São Paulo, v. 5, n. 2, p. 96-111, mai./ago. 2011. 